\title{
ELABORANDO UM PERFIL CONCEITUAL DE EQUAÇÃO: DESDOBRAMENTOS PARA O ENSINO E A APRENDIZAGEM DE MATEMÁTICA
}

\section{Developing a conceptual profile of equation: developments for the teaching and learning of Mathematics}

Alessandro Jacques Ribeiro ${ }^{1}$

Resumo: O modelo teórico Perfil Conceitual, desenvolvido por Eduardo Mortimer, vem sendo amplamente utilizado no Ensino de Ciências. Segundo esse modelo, conceitos polissêmicos permitem a elaboração de perfis conceituais, os quais são compostos de diferentes zonas, que correspondem a diferentes formas de ver, representar e significar o mundo. Não obstante, o trabalho de Alessandro Ribeiro identificou diferentes significados do conceito de equação. O conjunto desses significados recebeu o nome de Multissignificados de Equação. Assumindo o pressuposto de que o conceito de equação é polissêmico, buscou-se, neste trabalho, identificar e categorizar algumas zonas de um perfil conceitual de equação. Utilizando-se de um jogo dialógico entre dados de estudos epistemológicos e ontológicos, apresentamse as zonas preliminares de um perfil conceitual de equação: pragmática, geométrica, estrutural, processual e aplicacional. Nas considerações finais, são apontados os desdobramentos da pesquisa e algumas implicações da abordagem de perfil conceitual para o ensino e a aprendizagem de Matemática.

Palavras-chave: Significação. Equação. Perfil conceitual. Ensino de matemática. Aprendizagem. Educação algébrica.

\begin{abstract}
The theoretical model of a conceptual profile was developed by Eduardo Mortimer and has been widely used in science education. According to this model, polysemic concepts permitting the establishment of conceptual profiles, which are composed of different zones, that correspond to different ways of seeing, of representing and of signifying the world. Nevertheless, the research of Alessandro Ribeiro identified different meanings of the concept of equation. The set of these meanings was named by Multimeanings of Equation. Taking on the premise that the concept of equation is polysemous, this study aimed at identifying and categorizing some zones of a conceptual profile of equation. By using of a dialogical play between data from epistemological and ontological studies, zones of a conceptual profile of equation are presented: pragmatic, geometric, structural, procedural and applicational. Lastly, developments of the research and some implications of the conceptual profile approach to teaching and learning of mathematics are pointed out.
\end{abstract}

Keywords: Meaning. Equation. Conceptual profile. Mathematics teaching. Learning. Educational algebra.

${ }^{1}$ Centro de Matemática, Computação e Cognição (CMCC), Universidade Federal do ABC (UFABC). Rua Santa Adélia, n. 166, Bloco A, Torre 2, Sala 534, Bairro Bangu. Santo André, SP, Brasil. 09.210-170.

alessandro.ribeiro@ufabc.edu.br 
Ribeiro, A. J.

\section{Apresentação}

Em estudo anteriormente desenvolvido, identificou-se a existência de diferentes significados para o conceito de equação (RIBEIRO, 2007). Nesse trabalho de caráter teórico, o autor pôde observar, por meio de estudo epistemológico e didático, como diferentes povos, em diferentes épocas históricas, compreendiam e utilizavam o conceito de equação. Os resultados obtidos receberam o nome de Multissignificados de Equação.

Mortimer (1994) desenvolveu, em sua tese de doutorado, um modelo teórico denominado Perfil Conceitual. Segundo o autor, conceitos polissêmicos, como o de átomo, permitem a elaboração de perfis conceituais. Os perfis são compostos de diferentes zonas que correspondem a diferentes formas pelas quais os indivíduos veem, representam e dão significado ao mundo. As zonas são utilizadas pelas pessoas em diferentes contextos e podem conviver simultaneamente num mesmo indivíduo.

Buscando relacionar as ideias apresentadas por Ribeiro (2007) e por Mortimer (1994), o presente ensaio teórico tem o objetivo de identificar e categorizar algumas zonas que poderão compor um perfil conceitual de equação. $\mathrm{O}$ argumento de que o conceito de equação comporta um perfil conceitual é defendido neste trabalho, fundamentando-se nos resultados da pesquisa de Ribeiro (2007), assim como nas de Barbosa (2009) e de Dorigo (2010). Iniciase o artigo com uma discussão acerca da heterogeneidade de significados em educação matemática. A seguir, discorre-se sobre o modelo de perfil conceitual e o ensino de Matemática. Apresentam-se as zonas de um perfil conceitual de equação e finaliza-se com os desdobramentos de uma agenda de pesquisa, a qual destaca algumas possíveis implicações da abordagem do modelo de perfil conceitual para o ensino e a aprendizagem de Matemática.

\section{A heterogeneidade de significados em educação matemática}

Muito se discute e se pesquisa acerca da importância do estudo dos conceitos no ensino de ciências e de matemática (COELHO; CARVALHO, 2006; COUTINHO; MORTIMER; EL-HANI, 2007; NICOLLI; MORTIMER; 2009; PREDIGER, 2010; RIBEIRO, 2010; SOARES et al., 2007; ZIMER, 2008).

Kilpatrick et al. (2005) publicaram um importante trabalho acerca dos diferentes significados de conceitos matemáticos no âmbito da educação matemática. Esses autores chamam a atenção para uma particularidade, quando se trata da questão dos significados no ensino de matemática, visto que tais discussões englobam desde interpretações filosóficas e não filosóficas, passando por áreas como a psicologia, a sociologia, entre outras. Aliado a essa complexidade por eles apontada, há de se levar em conta que uma proposta que considere tal diversidade de significados para os conceitos matemáticos em salas de aula, certamente, deve contemplar, em seus pressupostos, a relação entre sujeito e meio sociocultural.

Os estudos apresentados e discutidos em Kilpatrick et al. (2005) vêm fomentando inquietações em relação à heterogeneidade de significados de conceitos matemáticos, em particular o conceito de equação. Segundo aqueles autores, significados em educação matemática podem - e por que não? - devem contemplar significados da matemática pura, significados da matemática escolar, significados do senso comum. Segundo eles: 
Várias maneiras de olhar para 'o significado de X', onde X é o conteúdo matemático a ser ensinado, são examinadas. Nós sugerimos que, devido aos significados em matemática escolar parecerem ser relativamente ambíguos, a necessidade de um desenvolvimento gradual é muitas vezes esquecida, com professores precisando tomar consciência de que todos os significados do 'dia a dia' em matemática são apenas parte da história. (KILPATRICK et al., 2005, p. 3, tradução nossa)

Em relação à problemática acima apontada, Howson (2005) explora diferentes significados para os números decimais, significados estes que estão relacionados com as esferas de prática em que estão inseridos. Enquanto isso, Skovsomose (2005) procura enfatizar as similaridades entre um processo de aprendizagem e um processo de ação, apontando a importância de se considerarem as intenções dos estudantes, quando estes estão inseridos em um ambiente de aprendizagem.

As discussões propostas nos trabalhos até aqui contemplados parecem apontar para o surgimento de dois importantes elementos a serem observados quando dos processos de ensino e de aprendizagem em matemática: (1) a heterogeneidade de significados e (2) o ambiente em que tais significados estão imersos.

Ao se colocar em discussão a relevância de tais elementos nos processos de ensino e de aprendizagem em Matemática, é importante considerar as contribuições de Vygotsky (1987), no que tange ao significado e ao sentido das palavras, na perspectiva da psicologia sóciohistórica.

Em seus trabalhos, Vygotsky defende que o significado de uma palavra aparece como algo estável e possível de ser compartilhado entre dois ou mais indivíduos. O sentido, por sua vez, depende da forma como tal palavra está sendo utilizada, e ele tende, assim, a ser uma formação mais dinâmica e complexa, na medida em que pode ser composto por diversas camadas que variam conforme sua estabilidade. Fundamentando-se nas ideias de Vygotsky, Moysés (1997, p. 39) aponta que

[...] o sentido de uma palavra depende da forma com que está empregada, isto é, do contexto no qual ela surge. O seu significado, no entanto, permanece relativamente estável. É formado por enlaces que foram associados à palavra ao longo do tempo, o que faz com que se considere o significado um sistema estável de generalizações, compartilhado por diferentes pessoas, embora com níveis de profundidade e amplitude diferentes.

Levando-se em conta as discussões e as reflexões acerca da heterogeneidade de significados que conceitos matemáticos podem assumir - em particular o conceito de equação - e considerando-se ainda questões referentes à importância do meio sociocultural na construção de tais significados, passa-se a discutir, na próxima seção deste artigo, a noção de perfil conceitual, buscando aproximar as discussões propostas inicialmente para a área das ciências, de maneira geral, daquelas que podem surgir, de maneira específica, no ensino de matemática. 
Ribeiro, A. J.

\section{Perfil conceitual e o ensino de matemática}

Como anunciado preliminarmente neste ensaio teórico, o desafio posto é o de apresentar algumas zonas na construção de um perfil conceitual de equação. Assim sendo, faz-se necessária a discussão do modelo teórico Perfil Conceitual, que vem sendo amplamente utilizado no ensino de ciências (COUTINHO; MORTIMER; EL-HANI, 2007; NICOLLI; MORTIMER, 2009; SOARES et al., 2007).

A noção de perfil conceitual foi desenvolvida e apresentada, inicialmente, na tese de doutorado de Eduardo Fleury Mortimer (1994). Esse modelo teórico considera

[...] a idéia de que um único conceito pode ter diferentes zonas que correspondem a diferentes maneiras de ver, representar e significar o mundo, e são usadas pelas pessoas em contextos diferenciados. [...] Segundo esta noção, qualquer indivíduo pode possuir mais de uma forma de compreensão de um determinado conceito, ou seja, diferentes zonas de um perfil conceitual podem conviver no mesmo indivíduo, correspondendo a formas distintas de pensar e falar, que podem ser usadas em contextos específicos. (COUTINHO; MORTIMER; EL-HANI, 2007, p. 116)

Segundo os estudos de Mortimer, conceitos como o de vida, o de morte, o de espécie são polissêmicos - admitem vários significados - e podem ser expressos por meio de um perfil conceitual. Outros estudos desenvolvidos por pesquisadores da área de Ensino de Física apontam possibilidades de se construir um perfil conceitual também para os conceitos de átomo e de calor, por exemplo.

A noção de perfil conceitual foi desenvolvida em complementaridade à noção de perfil epistemológico (BACHELARD, 1978). Entretanto, Mortimer (1994) aponta diferenças significativas em relação a este último conceito. Dentre tais diferenças, observa-se a ampliação da referida ideia proposta por Bachelard, uma vez que "perfil conceitual não se limita a aspectos epistemológicos, como na idéia original de Bachelard" (COUTINHO; MORTIMER; ELHANI, 2007, p. 116). Segundo observado pelos autores, "cada zona do perfil conceitual de um conceito pode ser tanto epistemológica como ontologicamente diferente de outras, já que essas duas características podem mudar à medida que nos movemos ao longo do perfil" (COUTINHO; MORTIMER; EL-HANI, 2007, p. 116).

Além das significativas diferenças entre os aspectos epistemológicos e os ontológicos encontrados no ensino e na aprendizagem de conceitos científicos, Coutinho, Mortimer e ElHani (2007), por exemplo, ressaltam a complementaridade entre a noção de perfil epistemológico e a noção de perfil ontológico para a constituição de um perfil conceitual.

No trabalho de Coutinho, Mortimer e El-Hani (2007) sobre a construção de um perfil conceitual para o conceito de vida, são discutidas e apresentadas as diferentes zonas que compõem tal perfil. A constituição dessas zonas levou em conta "um jogo dialógico entre estudos teóricos e empíricos, envolvendo pelo menos três domínios genéticos (WERTSCH, 1985): sociocultural; ontogenético; e microgenético" (COUTINHO; MORTIMER; EL-HANI, 2007, p. 116). 
Dentre as principais conclusões do referido trabalho, algumas delas são particularmente importantes para a proposta deste artigo: 1) a possibilidade de utilização da noção de perfil conceitual para o acompanhamento da evolução das ideias que os indivíduos podem ter de um determinado conceito; 2) a íntima relação entre a constituição das diferentes zonas de um perfil conceitual e a influência do contexto; 3) a tomada de consciência da diversidade de significados que um conceito pode admitir e as implicações deles para os processos de ensino e de aprendizagem dos conceitos que estão em jogo.

Vale ressaltar duas importantes propriedades que caracterizam um perfil conceitual: (1) um perfil conceitual é sempre individual, isto é, cada indivíduo pode exibir diferentes perfis - isto pode ser identificado pelas zonas que povoam esse perfil e pelo peso relativo de cada zona; (2) por outro lado, as zonas que constituem determinado perfil conceitual, em uma dada cultura, são sempre semelhantes. Em síntese, embora os perfis conceituais sejam individuais, tais perfis, em mesma cultura, são sempre os mesmos.

Com isso, a partir das discussões preliminares acerca do modelo teórico perfil conceitual, identificaram-se algumas afinidades e convergências com as reflexões apresentadas na seção anterior deste artigo, sobretudo naquilo que se refere à heterogeneidade de significados em educação matemática.

Além da visível relação entre as diferentes zonas de um perfil conceitual e a heterogeneidade de significados em educação matemática, há de se considerar a importância do meio sociocultural, quer na discussão e na legitimidade de significados em educação matemática, quer na determinação de cada zona de um perfil conceitual, como tem sido feito na área das ciências naturais, como a física, a química e a biologia.

Tomando como base a proposta de Mortimer (1994) para a constituição de um perfil conceitual, discutem-se, na próxima seção do presente artigo, os diferentes significados do conceito de equação identificados no trabalho de Ribeiro (2007), bem como os resultados das pesquisas de Barbosa (2009) e de Dorigo (2010).

\section{Algumas zonas de um perfil conceitual de equação}

A proposta deste trabalho é apresentar algumas zonas de um perfil conceitual de equação. As zonas até aqui identificadas e categorizadas resultaram das análises dos dados produzidos nos trabalhos de Ribeiro (2007), de Barbosa (2009) e de Dorigo (2010). Trata-se de três trabalhos de naturezas diversas, porém complementares. Ribeiro (2007) desenvolveu um trabalho de caráter teórico no qual buscou identificar diferentes significados do conceito de equação por meio de estudos epistemológico e didático. Em continuidade aos trabalhos de Ribeiro (2007), Barbosa (2009) e Dorigo (2010) propuseram-se a investigar se e como os significados identificados na pesquisa de Ribeiro estão presentes nas concepções de professores e alunos, respectivamente.

Considerando a centralidade dos resultados da tese de doutoramento de Ribeiro (2007) para a proposta anunciada neste artigo, discutem-se, a seguir tais resultados. O conjunto dos diferentes significados identificados - nomeados, por ele, multissignificados de equação compreende diferentes formas de ver, de interpretar e de tratar o conceito de equação. A problemática que se construiu nos estudos desenvolvidos na referida tese partiu da seguinte 
Ribeiro, A. J.

reflexão: "a percepção da existência de mais de um significado para equação levou-nos a desenvolver um estudo epistemológico e didático da noção de equação" (RIBEIRO; MACHADO, 2009, p. 121).

A análise de referenciais bibliográficos de natureza diversa - livros didáticos, livros de fundamentos da matemática, dicionários matemáticos e etimológicos, além de relatórios de pesquisas em educação matemática - revelou diferentes formas pelas quais diferentes povos, em diferentes épocas históricas, entendiam e utilizavam o conceito de equação.

Em Ribeiro (2007), perceberam-se, ao longo do desenvolvimento do estudo epistemológico, diferentes formas de se conceber e de se tratar o conceito de equação, em cada época histórica:

. Babilônios e egípcios: trabalhavam com equações que, em sua maior parte, eram originárias de problemas de ordem prática. O conceito de equação tinha basicamente um caráter pragmático, que, de forma intuitiva, igualava duas quantidades, com a finalidade de encontrar o valor da quantidade desconhecida. Na maior parte das vezes, a busca pelas soluções estava relacionada a equações particulares, para resolver problemas específicos, e os métodos utilizados estavam relacionados a ideias aritméticas, sem a preocupação de se encontrarem soluções gerais;

- Gregos: para eles, as equações já eram concebidas de maneira diferente dos babilônios e egípcios, pois não estavam procurando resolver equações que tinham sido originadas de problemas de ordem prática. O conceito de equação contemplava um caráter geométrico e, de forma dedutiva, a resolução repousava em manipulações geométricas. Percebe-se que, mesmo com a mudança de concepção acerca da álgebra nesse período - de aritmética, nos babilônios e egípcios, para geométrica, nos gregos - a busca pelas soluções ainda estava relacionada a equações particulares, e não a métodos gerais;

- Árabes e hindus: trabalhavam tanto com equações originárias de problemas de ordem prática quanto com situações que recaíam em interpretações e manipulações geométricas. O conceito de equação já tinha um caráter mais algébrico, mais generalista, pois estes povos passavam de um catálogo de expressões que se sabia resolver para um catálogo de todas as formas canônicas possíveis. Percebe-se, então, uma preocupação na busca de formas canônicas, como fez al-Khwarizmi ao estabelecer todas as possibilidades para o que conhecemos por trinômios de grau não superior a dois. Por outro lado, Ommar Khayyam já tinha uma concepção de equação mais relacionada a um caráter geométrico, interpretando as soluções das equações como a intersecção de curvas geométricas.

Em síntese, ao longo do estudo epistemológico realizado por Ribeiro (2007), identificou-se que: (1) babilônios e egípcios entendiam equação como um conceito que emergia de situações práticas, e buscavam resolvê-las de maneira intuitiva, com métodos que se apoiavam fortemente em ideias aritméticas; (2) gregos, por sua vez, sempre relacionavam equações a situações que envolviam conhecimentos geométricos, buscando as soluções, geralmente, por meio de raciocínios dedutivos; (3) árabes e hindus, bem como os europeus renascentistas, passam a conceber o conceito de equação de um ponto de vista estrutural.

Vale ressaltar que tanto babilônios, egípcios e gregos preocupavam-se sempre em resolver equações particulares, as quais estavam relacionadas a problemas ou a situações espe- 
cíficas. No entanto, árabes, hindus e os europeus renascentistas procuravam identificar, a partir da estrutura interna das equações, soluções gerais para uma classe de equações que apresentassem uma mesma estrutura.

A partir das reflexões e das análises propiciadas pelo estudo epistemológico, foi possível estabelecer um primeiro esboço, com algumas zonas de um perfil conceitual de equação. Vale lembrar que, neste momento, estão sendo consideradas, preliminarmente, as diferentes formas de se conceber e de tratar equação de um ponto de vista epistemológico, o qual se fundamenta no estudo ora apresentado (ver Quadro 1).

Quadro 1. Primeiras categorias identificadas e sua breve descrição.

\begin{tabular}{|l|l|}
\hline \multicolumn{1}{|c|}{ Categoria } & \multicolumn{1}{c|}{ Breve descrição } \\
\hline Pragmática & $\begin{array}{l}\text { Equação concebida a partir de problemas originários em contextos específicos, } \\
\text { geralmente de ordem prática. }\end{array}$ \\
\hline Intuitiva & $\begin{array}{l}\text { Busca por soluções particulares, as quais normalmente se fundamentam em } \\
\text { conhecimentos aritméticos. }\end{array}$ \\
\hline Geométrica & $\begin{array}{l}\text { Equação concebida a partir de situações envolvendo entes geométricos, geralmente } \\
\text { em contextos teóricos. }\end{array}$ \\
\hline Dedutiva & $\begin{array}{l}\text { Busca por soluções particulares, as quais são deduzidas a partir de conhecimentos } \\
\text { geométricos ou utilizando-se deles. }\end{array}$ \\
\hline Estrutural & $\begin{array}{l}\text { Equação concebida a partir de sua estrutura interna, independentemente do contexto } \\
\text { no qual está inserida. }\end{array}$ \\
\hline Generalista & $\begin{array}{l}\text { Busca por soluções gerais, para classes de equações, as quais geralmente se } \\
\text { fundamentam em conhecimentos algébricos. }\end{array}$ \\
\hline
\end{tabular}

Fonte: Elaborado pelo autor.

Dando continuidade ao seu trabalho, Ribeiro (2007) desenvolveu um estudo didático que possibilitou a observação de outros significados para o conceito de equação. É fato que alguns desses novos significados tiveram forte influência das reflexões que nasceram a partir da elaboração do estudo epistemológico, fato esse ratificado pelo próprio autor ao longo de sua tese de doutoramento.

A partir do caráter estrutural dado ao conceito de equação, observado nos árabes, nos hindus e nos europeus renascentistas, pôde-se notar que, por ocasião do Movimento da Matemática Moderna (MMM) ou em seus reflexos no/para o ensino de Matemática, as situações encontradas em livros didáticos e/ou em resultados de pesquisas em educação matemática contemplavam esse mesmo caráter estrutural das equações. No entanto, considerando-se os princípios norteadores do MMM, é natural que se observe o forte 'apelo conjuntista' impresso nas situações matemáticas em questão.

Ainda no que se refere ao estudo didático, em resultados de pesquisas em educação matemática, bem como em alguns livros didáticos para a educação básica, observou-se, para o estudo das equações, uma abordagem intimamente relacionada a processos e a técnicas para sua resolução. 
Ribeiro, A. J.

Um último, porém não menos importante significado surgiu, à medida que Ribeiro (2007) analisou parte da obra de Chevallard (1991), no que se refere à transposição didática. No trabalho em questão, Chevallard (1991) afirma que equação não é uma noção matemática e, assim, não pode ocupar o status de saber a ser ensinado. Por entender que tal assertiva feita por Chevallard (1991) parecia estar fundamentada no fato de não haver uma definição precisa de equação, Ribeiro (2007) propõe que não há necessidade de definir o conceito de equação para poder contemplá-lo nas aulas de matemática. Assim posto, Ribeiro (2007) categoriza uma outra forma de conceber, de tratar o conceito equação, admitindo-a como uma noção primitiva.

Enfim, considerando-se os resultados do estudo didático acima apresentado, foi possível estabelecer um outro esboço, com novas zonas para o perfil conceitual de equação, as quais são apresentadas no Quadro 2.

Quadro 2. Novas categorias identificadas e sua breve descrição.

\begin{tabular}{|l|l|}
\hline \multicolumn{1}{|c|}{ Categoria } & \multicolumn{1}{c|}{ Breve descrição } \\
\hline Conjuntista & $\begin{array}{l}\text { Equação normalmente reconhecida como uma ferramenta intimamente ligada ao } \\
\text { conceito de função, de relação entre conjuntos. }\end{array}$ \\
\hline Processual & Equação concebida a partir de seus próprios processos de resolução. \\
\hline Tecnicista & Busca por soluçães geralmente relacionadas a alguma técnica ou algoritmo particular. \\
\hline Axiomática & Equação concebida como uma noção primitiva, sem necessidade de uma definição. \\
\hline
\end{tabular}

Fonte: Elaborado pelo autor.

Ao analisar de forma mais ampla e global o conjunto de dados que emergiram dos estudos epistemológicos e didáticos feitos por Ribeiro (2007), e considerando a proposta de identificar zonas de um perfil conceitual a partir de uma grande variedade de fontes e de contextos nos quais os diversos significados estão inseridos ou são empregados, pretende-se, no Quadro 3, apresentar uma tentativa de expressar um 'diálogo' entre os significados até aqui identificados.

Ao se produzir uma nova categorização das zonas identificadas a partir dos dados obtidos e discutidos até o momento, procura-se elaborar outra nomenclatura e/ou descrições que sejam capazes de harmonizar pequenos ajustes que se fizeram necessários na/para a construção das novas zonas (Quadro 3).

Dando continuidade às discussões e às análises rumo à construção de algumas zonas de um perfil conceitual de equação, inserem-se, na discussão, alguns resultados das pesquisas de Barbosa (2009) e Dorigo (2010), as quais fortaleceram os pressupostos para a elaboração das (novas) categorias apresentadas no Quadro 3. 
Elaborando um perfil conceitual de equação: ...

Quadro 3. Novas categorias que relacionam as dos quadros 1 e 2, e sua breve descrição.

\begin{tabular}{|l|l|l|}
\hline \multicolumn{1}{|c|}{ Categoria } & \multicolumn{1}{|c|}{ Breve descrição } & \multicolumn{1}{|c|}{ Categoria(s) originária(s) } \\
\hline Pragmática & $\begin{array}{l}\text { Equação interpretada a partir de problemas de ordem } \\
\text { prática. Equação admitida como uma noção primitiva. } \\
\text { Busca pela solução predominantemente aritmética. }\end{array}$ & $\begin{array}{l}\text { Pragmática. Intuitiva. } \\
\text { Axiomática. }\end{array}$ \\
\hline Geométrica & $\begin{array}{l}\text { Equação interpretada a partir de problemas geométricos. } \\
\text { Busca pela solução predominantemente geométrica. }\end{array}$ & Geométrica. Dedutiva. \\
\hline Estrutural & $\begin{array}{l}\text { Equação interpretada a partir de sua estrutura interna. } \\
\text { Busca pela solução predominantemente algébrica. }\end{array}$ & $\begin{array}{l}\text { Estrutural. Generalista. } \\
\text { Tecnicista. }\end{array}$ \\
\hline Processual & $\begin{array}{l}\text { Equação interpretada a partir de processos de resolução. } \\
\text { Busca pela solução aritmética ou algébrica. }\end{array}$ & $\begin{array}{l}\text { Processual. Tecnicista. } \\
\text { Intuitiva. }\end{array}$ \\
\hline Aplicacional & $\begin{array}{l}\text { Equação interpretada a partir de suas aplicaçães. Busca } \\
\text { pela solução aritmética ou algébrica. }\end{array}$ & $\begin{array}{l}\text { Pragmática. Conjuntista. } \\
\text { Intuitiva. }\end{array}$ \\
\hline
\end{tabular}

Fonte: Elaborado pelo autor.

Como apontado anteriormente, as pesquisas ${ }^{2}$ de Barbosa (2009) e Dorigo (2010) surgiram com o propósito de dar continuidade aos trabalhos iniciados por Ribeiro (2007) e, embora tenham tido professores e alunos como fonte de dados, caracterizaram-se como pesquisas diagnósticas, ou seja, não houve nenhum tipo de intervenção nos processos de ensino e de aprendizagem de equações envolvendo tais atores. Essa questão será retomada ao final do presente artigo, em argumentação que justifica e fortalece a necessidade de continuidade da agenda de pesquisa que aqui se abre.

Apresentam-se, a seguir, algumas análises feitas em Barbosa (2009) e Dorigo (2010), as quais convergem para o tema central deste trabalho, trazendo subsídios para a categorização das zonas até aqui identificadas.

Em ambas as pesquisas, foi identificada uma forte incidência do significado intuitivopragmático, tanto nas concepções de professores como nas dos alunos. Entretanto, aparece com mais naturalidade, nos resultados de Dorigo (2010), a 'utilização' de tal significado, ainda que os alunos sintam uma grande necessidade de utilizarem procedimentos e técnicas (significado processual-tecnicista) para tratar as situações às quais foram expostos.

\footnotetext{
${ }^{2}$ Vale acrescentar que Barbosa (2009) utilizou-se de entrevistas semiestruturadas para coletar seus dados, as quais foram realizadas individualmente com cada professor. Dorigo (2010) trabalhou com grupos de alunos distribuídos em duplas, ambientados num contexto de um 'espaço de discussão'. Em ambos os casos, as intervenções que ocorreram foram no sentido de possibilitar uma maior 'explicitação' das concepções de equação que tais alunos e professores possuíam.
} 
Ribeiro, A. J.

Por outro lado, na pesquisa de Barbosa (2009), a presença do significado processualtecnicista é mais aparente e frequente, se comparada com a pesquisa de Dorigo (2010). Segundo Barbosa (2009), os professores investigados encontraram dificuldades para tratar as situações matemáticas em que se envolveram, quando não se recordavam de uma fórmula e/ou um algoritmo de resolução. Embora tais professores também 'utilizem' o significado intuitivopragmático, parecem não se sentir tão à vontade para usar estratégias aritméticas, como foi observado entre os alunos.

$\mathrm{Na}$ intenção de ilustrar e de fundamentar as discussões acima contempladas, apresentam-se, a seguir, duas das situações matemáticas que foram utilizadas nas pesquisas de Barbosa (2009) e de Dorigo (2010). Uma das situações matemáticas escolhidas está relacionada ao significado intuitivo-pragmático, e, a outra, relacionada ao significado processual-tecnicista. Vale lembrar que ambas as situações foram contempladas nas duas pesquisas, ou seja, foram vivenciadas tanto por professores como por alunos.

Situação 1: situação matemática que remete ao significado intuitivo-pragmático, uma vez que a equação emerge de uma situação do cotidiano (pragmático) e pode ser tratada numericamente, utilizando-se de conhecimentos já adquiridos pelos indivíduos (intuitivo).

- Uma aluna, Bianca, fã de música, reserva, num certo mês, R \$70,00 para a compra de CDs ou DVDs. Um CD custa R\$12,00 e um DVD custa R\$16,00. Quais as possibilidades de compra desses dois bens, gastando exatamente os $\mathrm{R} \$ 70,00$ ?

Figura 1. Protocolo 1 (professor A)

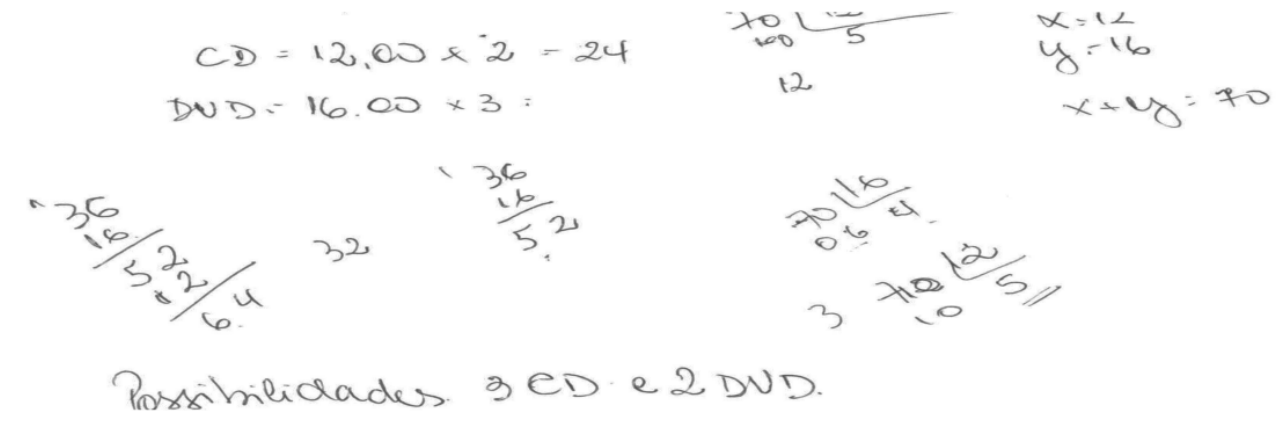

Fonte: Barbosa (2009) 
Elaborando um perfil conceitual de equação: ...

Transcrição (Professor B)

"Por tentativa assim eu não consegui achar qual seria as possibilidades, sem usar fórmula nenbuma, tentando assim, por tentativa, colocando, comprando dois DVDs, um CD, não sei o quê... ou então usando..."

Figura 2. Protocolo (professor C)

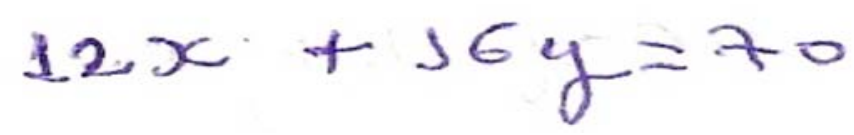

Fonte: Barbosa (2009).

Transcrição (Professor C)

"Se en atribuir valores para $x$ e para y, se não, não dá, ou se eu tivesse outra equação montar um sistema."

Figura 3. Protocolo (Alunos - Dupla 1)

$$
\begin{aligned}
& 1 D V D+4 C D S=R \$ 64,00 \\
& 2 D V D_{s}+3 C D_{s}=R S 68, C 0 \\
& 3 D D_{s}+2 C D_{s}=R S 72,00 \\
& 4 D V D s+1 C D=12576,00 \\
& \text { Cenclusaie: nó hà renturma passibiliclede de } \\
& \text { compro desses dois bens, gastondo exctamente } \\
& \text { R\$70,00 }
\end{aligned}
$$

Fonte: Dorigo (2010).

Transcrição (Alunos Dupla 1)

"Não reconhecemos e nem utilizamos equação. Pensamos que a melhor forma seria, ou a única forma que sabiamos de resolver era "chutando" para encontrar o resultado."

Situação 2: situação matemática que remete ao significado processual-tecnicista, uma vez que a equação está relacionada aos processos e técnicas de resolução e de busca pela resposta da situação.

- Determine os valores de y para os quais a expressão $(y-1)^{2}$ é igual a $-4 y$. 
Ribeiro, A. J.

Figura 4. Protocolo (professor B)

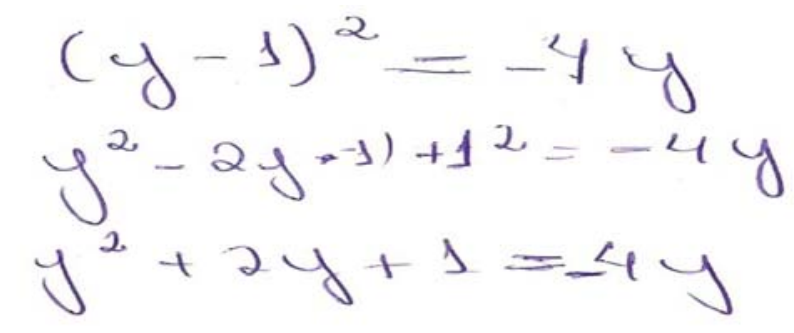

Fonte: Barbosa (2009).

Transcrição (Professor B)

"Então eu cheguei num ponto aqui que ou eu errei o sinal, ou raiz de 32 não vai ter como conseguir, algum passo aqui deve estar... alguma coisa que não está... se for para achar o valor no caso aqui, raiz. de 32... aqui alguma coisa..."

P. "Não existe raiz de 32?"

B. "Não, assim... só nos números complexos, né?"

Figura 5. Protocolo (Alunos - Dupla 1)

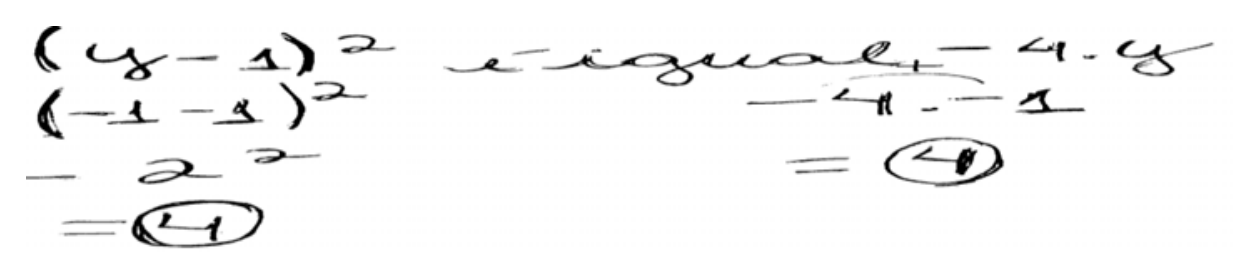

Fonte: Dorigo (2010).

Transcrição (Alunos Dupla 1)

"Não reconbecemos e nem utilizamos equação. Pensamos que a melhor forma seria, ou a única forma que sabiamos de resolver era 'chutando' para encontrar o resultado."

Outra característica revelada tanto pela pesquisa de Barbosa (2009) como pela de Dorigo (2010) influenciou a reorganização, neste trabalho, dos significados originalmente propostos por Ribeiro (2007): a divergência entre os significados que compõem os Multissignificados de Equação e as produções de professores e alunos. Ocorre a convergência quando os

Ciência \&̊ Educação, v. 19, n. 1, p. 55-71, 2013 
significados de equação propostos nas situações matemáticas são os mesmos das produções dos indivíduos que com elas interagem. Por exemplo: nas pesquisas de Barbosa (2009) e Dorigo (2010), foi elaborada uma situação matemática como 'representante' do significado intuitivo-pragmático: a equação origina-se de um problema de ordem prática, e a solução pode ser encontrada utilizando-se conhecimentos aritméticos. Porém, tanto os professores como os alunos por eles investigados escreveram uma equação para o problema e encontraram a solução por meio de alguma técnica algébrica ou algoritmo conhecidos.

Apoiada nesses resultados, surgiu a necessidade de se repensarem as categorias elaboradas originalmente em Ribeiro (2007). A partir das pesquisas até aqui discutidas, observou-se que nem sempre havia a convergência entre o significado proposto e o significado utilizado. Corroborando tal assertiva estão os pressupostos teóricos do modelo perfil conceitual. $\mathrm{Na}$ metodologia empregada, para identificar as zonas de um perfil conceitual, é importante considerar um jogo dialógico entre o epistemológico e o ontológico. E é justamente isto que está sendo inicialmente proposto neste trabalho: provocar um diálogo entre o epistemológico, a partir dos dados da pesquisa de Ribeiro (2007), e o ontológico, a partir dos dados das pesquisas de Barbosa (2009) e Dorigo (2010).

Por fim, na próxima seção deste artigo, serão apresentadas as considerações e as reflexões finais. Pretende-se apontar algumas implicações para o ensino de matemática, bem como discutir os encaminhamentos que estão sendo levados a cabo como desdobramentos das reflexões aqui postas.

\section{Reflexões finais: desdobramentos da pesquisa em busca de um perfil conceitual de equação e possíveis implicações para o ensino de matemática}

Uma vez que o objetivo principal deste trabalho é apresentar estudos preliminares acerca de um perfil conceitual de equação, identificando e categorizando, a partir do diálogo entre o epistemológico e o ontológico, algumas zonas que compõem um perfil conceitual de equação, divide-se esta última seção do artigo em: (1) desdobramentos desses estudos preliminares em busca de novas zonas do perfil conceitual em construção, sobretudo no que se refere ao nível ontológico, e (2) algumas reflexões sobre implicações da abordagem do modelo do perfil conceitual para o ensino de Matemática.

Como já explorado anteriormente neste trabalho, o modelo dos perfis conceituais busca identificar diferentes zonas - construídas com base em pressupostos epistemológicos e ontológicos diferentes de um determinado conceito científico - que correspondem a diferentes maneiras de ver, de representar e de significar um conceito.

Coutinho, Mortimer e El-Hani (2007) propõem as zonas para um perfil conceitual de vida. É importante destacar que essas zonas foram identificadas

[...] a partir de questionários aplicados a alunos de um curso de graduação em Ciências Biológicas, num jogo dialógico com resultados obtidos em estudos históricos e epistemológicos sobre o conceito de vida, na literatura sobre concepções alternativas sobre vida e na análise de 
Ribeiro, A. J.

livros didáticos do Ensino Superior. Utilizamos esse perfil como um instrumento de análise dos modos de falar sobre o conceito de vida dos alunos de uma Graduação em Ciências Biológicas e de cursos de Pós-Graduação em Ecologia e em Genética. No caso desses últimos alunos, empregamos entrevistas baseadas em situações-problema para investigar a tomada de consciência de seus perfis conceituais. (COUTINHO; MORTIMER; EL-HANI, 2007, p. 134)

A metodologia proposta na pesquisa acima, bem como em outras desenvolvidas por pesquisadores que investigam perfis conceituais (por exemplo, NICOLLI; MORTIMER, 2009; SOARES et al., 2007), leva em conta a dialogicidade entre os dados de natureza epistemológica e ontológica, como já apontado ao longo deste artigo. É importante que se destaque a necessidade de fontes diversas e variadas para a identificação das zonas que compõem um perfil conceitual de determinado conceito.

Com isso, tomando-se os pressupostos teóricos e metodológicos intrínsecos à constituição de um perfil conceitual, bem como suas implicações para os processos de ensino e de aprendizagem em Ciências - os quais serão retomados e relacionados ao Ensino de Matemática em seguida -, entende-se que é relevante a proposta aqui defendida de construção de um perfil conceitual de equação, no âmbito da educação matemática.

Admitindo-se tal premissa, discorre-se a seguir sobre o que já foi feito e o que ainda precisa ser estudado para que se constitua um perfil conceitual de equação. Observe-se: (1) se um perfil conceitual é constituído em parte por pressupostos epistemológicos, os resultados obtidos em Ribeiro (2007) foram utilizados para compor algumas das zonas desse perfil (quadros 1 e 2); (2) por outro lado, as zonas de um perfil conceitual também se constituem a partir de pressupostos ontológicos, os quais devem estabelecer um jogo dialógico e devem considerar diferentes domínios genéticos (WERTSCH, 1985), bem como a heterogeneidade de vozes (WERTSCH, 1991). Nesse sentido, deu-se início a essa dinâmica quando da elaboração das pesquisas de Barbosa (2009) e Dorigo (2010) e, a partir dos resultados desses estudos, estabeleceram-se novas zonas para o perfil conceitual de equação (quadro 3).

Entretanto, é mister considerar que os dados obtidos nas pesquisas de Barbosa (2009) e Dorigo (2010) são limitados, tanto do ponto de vista quantitativo como qualitativo, quando se consideram as propostas e as orientações de outras pesquisas que discutem perfis conceituais, como as indicadas acima. Assim, agenda-se aqui o compromisso de dar continuidade às investigações iniciadas até o momento (BARBOSA, 2009; DORIGO, 2010; RIBEIRO, 2007, 2010), as quais devem envolver: (1) uma quantidade maior e mais diversificada de pessoas (por exemplo: alunos de cursos de graduação e pós-graduação em matemática e em educação matemática, professores de diferentes níveis de ensino e com diferentes formações etc.); (2) instrumentos e procedimentos de coleta de dados diversos, os quais contemplem as zonas apresentadas neste artigo, bem como outros tipos e formas de questionamentos que permitam identificar as diferentes maneiras pelas quais os indivíduos compreendem e utilizam o conceito de equação em diferentes contextos. 
Elaborando um perfil conceitual de equação: ...

Feito isso, pretende-se ter dados e elementos suficientes para ampliar, aprofundar e reestruturar as zonas identificadas até o momento, que compõem um perfil conceitual de equação (ver Quadro 4).

Quadro 4. Zonas identificadas e sua breve descrição.

\begin{tabular}{|l|l|}
\hline \multicolumn{1}{|c|}{ Categoria } & \multicolumn{1}{c|}{ Breve descrição } \\
\hline Pragmática & $\begin{array}{l}\text { Equação interpretada a partir de problemas de ordem prática. Equação admitida como } \\
\text { uma noção primitiva. Busca pela solução predominantemente aritmética. }\end{array}$ \\
\hline Geométrica & $\begin{array}{l}\text { Equação interpretada a partir de problemas geométricos. Busca pela solução } \\
\text { predominantemente geométrica. }\end{array}$ \\
\hline Estrutural & $\begin{array}{l}\text { Equação interpretada a partir de sua estrutura interna. Busca pela solução } \\
\text { predominantemente algébrica. }\end{array}$ \\
\hline Processual & $\begin{array}{l}\text { Equação interpretada a partir de processos de resolução. Busca pela solução } \\
\text { aritmética ou algébrica. }\end{array}$ \\
\hline Aplicacional & $\begin{array}{l}\text { Equação interpretada a partir de suas aplicações. Busca pela solução aritmética ou } \\
\text { algébrica. }\end{array}$ \\
\hline
\end{tabular}

Fonte: Elaborado pelo autor.

As reflexões finais do presente trabalho parecem apontar possibilidades de incorporação de uma abordagem baseada no modelo dos perfis conceituais nas aulas de Matemática. Por um lado, parece ser possível, com tal abordagem, instrumentalizar os professores para que possam compreender a diversidade de significados - aqui chamados de zonas - que podem compor os conhecimentos de seus alunos. Tal metodologia, assim como é defendido por Coutinho, Mortimer e El-Hani (2007), por exemplo, pode abrir caminho para que as salas de aulas se tornem, cada dia mais, espaços ricos de interação e de diálogo entre alunos, professores e os conhecimentos de determinada área. Com isso, podem-se propiciar novos e interessantes contextos de produção e negociação de significados.

Entretanto, assim como se faz necessária a investigação mais sistemática e ampla de identificação das zonas de um perfil conceitual de equação, também o será a urgência de compreender se e como uma abordagem de ensino fundamentada no modelo dos perfis conceituais contribui para uma melhor aprendizagem de Matemática em salas de aula da Educação Básica e da formação de professores. 
Ribeiro, A. J.

\section{Referências}

BACHELARD, G. O novo espírito científico. São Paulo: Abril Cultural, 1978. (Coleção Os pensadores).

BARBOSA, Y. O. Multisignificados de equação: uma investigação sobre as concepções de professores de Matemática. 2009. 196 f. Dissertação (Mestrado em Educação Matemática) - Universidade Bandeirante de São Paulo, São Paulo, 2009.

CHEVALLARD, Y. La transposition didactique. Grenoble: La Pensée Sauvage, 1991.

COELHO, M. A. V. M. P.; CARVALHO, D. L. O estudo do discurso em educação matemática: a problematização de significados hegemônicos sobre resolução de problemas. Paradigma, Maracay, v. 27, n. 2, p. 253-276, dez. 2006.

COUTINHO, F. A.; MORTIMER, E. F.; EL-HANI, C. N. Construção de um perfil conceitual para o conceito biológico de vida. Investigações em Ensino de Ciências, Porto Alegre, v. 12, n. 1, p. 115-137, 2007.

DORIGO, M. Investigando as concepções de equação de um grupo de alunos do ensino médio. 2010. 137 f. Dissertação (Mestrado em Educação Matemática) Universidade Bandeirante de São Paulo, São Paulo, 2010.

HOWSON, G. "Meaning” and school mathematics. In: KILPATRICK, J. et al. (Ed.). Meaning in mathematics education. New York: Springer, 2005. p. 17-38.

KILPATRICK, J. et al. (Ed.). Meaning in mathematics education. New York: Springer, 2005.

MORTIMER, E. F. Evolução do atomismo em sala de aula: mudanças de perfis conceituais. 1994. 281 f. Tese (Doutorado em Educação) - Faculdade de Educação, Universidade de São Paulo, São Paulo, 1994.

Conceptual change or conceptual profile change? Science $\boldsymbol{\&}$ Education, Dordrecht, v. 4, n. 3, p. 267-285, 1995.

MOYSÉS, L. Aplicações de Vygostsky à educação matemática. Campinas: Papirus, 1997.

NICOLLI, A. A.; MORTIMER, E. F. Construção de um perfil conceitual de morte. In: ENCONTRO NACIONAL DE PESQUISA EM EDUCAÇÃO EM CIÊNCIAS, 7., 2009, Florianópolis. Anais... Belo Horizonte: Associação Brasileira de Pesquisa em Educação em Ciências, 2009. p. 1-12.

PREDIGER, S. How to develop mathematics-for-teaching and for understanding: the case of meanings of the equal sign. Journal of Mathematics Teacher Education, Dordrecht, v. 13, n. 1, p. 73-93, 2010.

RIBEIRO, A. J. Equação e seus multisignificados no ensino de matemática: contribuições de um estudo epistemológico. 2007. 144 f. Tese (Doutorado em Educação Matemática) - Pontifícia Universidade Católica, São Paulo, 2007.

Ciência \&̊ Educação, v. 19, n. 1, p. 55-71, 2013 
Elaborando um perfil conceitual de equação: ...

RIBEIRO, A. J. Uma proposta de construção de perfil conceitual de equação: implicações para a educação matemática. Boletim GEPEM, Rio de Janeiro, n. 56, p. 31-44, 2010.

RIBEIRO, A. J.; MACHADO, S. D. A. Equação e seus multisignificados: potencialidades para a construção do conhecimento matemático. Zetetiké, Campinas, v. 17, n. 31, p. 109128, 2009.

SKOVSMOSE, O. Meaning in mathematics education. In: KILPATRICK, J. et al. (Ed.). Meaning in mathematics education. New York: Springer, 2005. p. 83-100.

SOARES, A. et al. Estudos preliminares sobre o perfil conceitual de espécie em alunos do ensino médio. In: ENCONTRO NACIONAL DE PESQUISA EM EDUCAÇÃO EM CIÊNCIAS, 6., 2007, Florianópolis. Anais... Belo Horizonte: Associação Brasileira de Pesquisa em Educação em Ciências, 2007. v. 1, p. 1-12.

VYGOTSKY, L. S. Pensamento e linguagem. São Paulo: Martins Fontes, 1987.

WERTSCH, J. Vygotsky and the social formation of mind. Cambridge: Harvard University Press, 1985.

Voices of mind: a socialcultural approach to mediated action. Cambridge: Harvard University Press, 1991.

ZIMER, T. T. B. Aprendendo a ensinar matemática nas séries iniciais do ensino fundamental. 2008. 308 f. Tese (Doutorado em Educação) - Faculdade de Educação, Universidade de São Paulo, São Paulo, 2008.

Artigo recebido em 21/03/12. Aceito em 27/10/12.

71 